\title{
Vitamin D deficiency is endemic in Middle Eastern sportsmen
}

\author{
Bruce Hamilton*, Justin Grantham, Sebastien Racinais and Hakim Chalabi \\ ASPETAR, Qatar Orthopaedic and Sports Medicine Hospital, PO Box 29222, Doha, Qatar
}

Submitted 6 July 2009: Accepted 7 December 2009: First published online 15 January 2010

\begin{abstract}
Objective: While vitamin D deficiency is well recognized in Middle Eastern women as a result of cultural norms of remaining covered, Middle Eastern men are an under-reported group. Vitamin D is now known to have multiple effects, including an impact on muscle function, thereby increasing the relevance for sportsmen. The aim of the present study was to evaluate serum 25-hydroxyvitamin D (25(OH)D) levels in young male Middle Eastern athletes.

Design: Cross-sectional study.

Setting: Qatar Orthopaedic and Sports Medicine Hospital, Doha, Qatar.

Subjects: Ninety-three Middle Eastern men presenting to hospital for an annual screening undertook a blood test to evaluate their vitamin D status.

Results: Ninety-one per cent of athletes were found to be deficient in $25(\mathrm{OH}) \mathrm{D}$ (serum concentration $<20 \mathrm{ng} / \mathrm{ml}$ ). Athletes with severe deficiencies were significantly younger than those with less marked deficiency. A subset of athletes underwent bone mineral density assessment and 59\% were shown to have at least one $Z$-score less than -1 ; despite this, however, no athletes reported a stress fracture. There was no correlation between $25(\mathrm{OH}) \mathrm{D}$ concentration and sunlight exposure, skin coverage and skin colouring.

Conclusions: The study revealed that $25(\mathrm{OH}) \mathrm{D}$ deficiency is very common among otherwise healthy Middle Eastern male athletes. Given the potentially significant long- and short-term effects of 25(OH)D deficiency, serum 25(OH)D evaluation should be part of the routine assessment in this region.
\end{abstract}

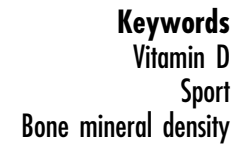

Keywords

Sport

Bone mineral density
Vitamin D is produced in the skin, under the influence of UVB sunlight converting 7-dehydrocholesterol to previtamin $\mathrm{D}_{3}$, with lesser quantities also found in the diet in the form of both vitamin $\mathrm{D}_{2}$ (ergocalciferol) and vitamin $\mathrm{D}_{3}$ (cholecalciferol). In the dermis, pre-vitamin $\mathrm{D}_{3}$ is rapidly converted to vitamin $\mathrm{D}_{3}$, prior to its subsequent conversion to 25-hydroxyvitamin D $(25(\mathrm{OH}) \mathrm{D})$ in the liver. Further hydroxylation of $25(\mathrm{OH}) \mathrm{D}$ to the active form of vitamin $\mathrm{D}$, 1,25-dihydroxyvitamin $\mathrm{D}\left(1,25(\mathrm{OH})_{2} \mathrm{D}\right)$, occurs in the kidneys $^{(1)} \cdot 1,25(\mathrm{OH})_{2} \mathrm{D}$ is a hormone essential for Ca homeostasis and bone mineralization but is increasingly being recognized as having effects on various organs ${ }^{(2)}$, with $1,25(\mathrm{OH})_{2} \mathrm{D}$ receptors found in the nucleus of most tissues $^{(3)}$. In addition to its role in Ca homeostasis, vitamin D has also been implicated in osteoporotic fractures, bowel cancer, arthritis, diabetes and CVD ${ }^{(1,2,4-12)}$.

While the definition of both vitamin D deficiency and appropriate supplementation levels continues to be hotly debated $^{(13)}$, it is generally accepted that serum $25(\mathrm{OH}) \mathrm{D}$ concentrations of $20-30 \mathrm{ng} / \mathrm{ml}$ represent insufficiency, concentrations below $20 \mathrm{ng} / \mathrm{ml}$ deficiency, and concentrations below $10 \mathrm{ng} / \mathrm{ml}$ severe deficiency ${ }^{(1)}$. Deficiency of vitamin $\mathrm{D}$ is now recognized as endemic in many regions of the world including North America,
Europe and the Middle East ${ }^{(14-20)}$. With the most common cause of vitamin D deficiency being inadequate sunlight exposure, it is not surprising that countries at higher latitude have high incidence of deficiency ${ }^{(18)}$. However, more recently, inner-city young adults in America have been found to be deficient in vitamin $D^{(16,21)}$. Despite high sunlight hours, vitamin D deficiency is well described in women in the Middle East, primarily as a result of cultural norms of keeping skin covered ${ }^{(22,23)}$.

With the majority of vitamin D studies in the Middle East focusing on women ${ }^{(15,22-24)}$, young men appear to be an under-recognized at-risk group ${ }^{(15,25)}$. Indeed, in the 1980 s, $73 \%$ of young Saudi Arabian men were found to have $25(\mathrm{OH}) \mathrm{D}$ levels less than $10 \mathrm{ng} / \mathrm{ml}^{(26)}$. Despite this evidence, it has been anticipated that as a result of high sunshine hours, vitamin D levels in young male athletes would be within normal limits, especially those who regularly participate in outdoor sports. However, athletes are not immune to vitamin D deficiency and concern has recently been raised about the vitamin D status of athletes ${ }^{(27)}$ : both elite female Australian gymnasts and Finnish female athletes were recently found to be deficient in $25(\mathrm{OH}) \mathrm{D}^{(21,28)}$. Furthermore, while little is known of any performance impact of 25(OH)D deficiency, some authors suspect it 
may be a marked impediment when not available in adequate doses ${ }^{(29)}$. Indeed, despite limited scientific evidence at the time, in the early part of the 20th century athletes were allegedly using UVB rays as an ergogenic aid $^{(30,31)}$ and recently authors have proposed that $25(\mathrm{OH}) \mathrm{D}$ deficiency may in fact impact upon exercise performance in young women ${ }^{(32,33)}$. For example, in a recent study of ninety-nine postmenarchal adolescent girls in England, Ward et al. ${ }^{(32)}$ found a positive relationship between serum 25(OH)D level and jump height, jump velocity and power. In addition to any immediate performance deficits for athletes, 25(OH)D deficiency may have both immediate effects on health such as stress fractures, as well as substantial long-term health impacts $^{(4,34,35)}$. Subsequently the identification and correction of any deficiency is of paramount importance.

In the present study we aimed to evaluate the $25(\mathrm{OH}) \mathrm{D}$ status and risk factors for $25(\mathrm{OH}) \mathrm{D}$ deficiency in young male Middle Eastern athletes.

\section{Methodology}

\section{Participants and procedure}

Ethical approval for the study was obtained from the Qatar Orthopaedic and Sports Medicine Hospital ethics committee, and all athletes completed an informed consent to participate. All athletes who attended the Qatar Orthopaedic and Sports Medicine Hospital for a preparticipation medical evaluation between 9 April and 16 October 2008 undertook a blood test to evaluate their vitamin D status. This included the assessment of serum $25(\mathrm{OH}) \mathrm{D}$, serum $1,25(\mathrm{OH})_{2} \mathrm{D}$, plasma parathyroid hormone (PTH), total Ca, phosphate and alkaline phosphatase (ALP). In addition, with the assistance of a nurse, subjects completed a vitamin D questionnaire. Athletes in this sample ranged from professional or semi-professional to amateur and junior sports participants in sports including football, athletics, handball, shooting, squash, cycling, martial arts and body-building. In addition, football referees were included in this sample as they train and participate in a similar manner to football participants in Qatar. Screened athletes were excluded from the study if female, if they declined consent to participate in the study, were not of Middle Eastern birth place or did not complete key components (i.e. questionnaire) of the vitamin $\mathrm{D}$ screening process within the prescribed study period.

Of a total sample size of 449 athletes who were screened between April and October, ninety-three Middle Eastern sportsmen completed all requirements and were eligible for the study (age 21.3 (SD 6.9) years; range 13-45 years). Country of origin included Qatar ( $n 81)$, Iraq $(n 4)$, Oman ( $n 3$ ), Iran ( $n 2)$ and one each from Bahrain, Jordan and Syria. A smaller subset (thirty-nine athletes) also underwent a bone density assessment.

\section{Questionnaire}

The questionnaire addressed specific areas relevant to exercise and vitamin D risk analysis. This included: training and competition (indoors and outdoors percentage); skin exposure (nil, hands and face only, more than hands and face); daily sunlight exposure in last month (nil or <30 min, 30-60 min, 60-120 min, >120 min); sunscreen use (yes, no); previous history of stress fracture, fracture, gastrointestinal problems, smoking, alcohol (yes, no); family history of osteoporosis, fractures or diabetes (yes, no); supplements and medication use; nurse assessment of skin colour (dark, olive, fair).

\section{Laboratory analyses}

A portion of each blood sample was separated for immediate analysis ( $\mathrm{Ca}, \mathrm{Mg}$, phosphate, ALP). Total Ca was measured using a modified calcium $o$-cresolphthalein complexone reaction, $\mathrm{Mg}$ by a modified methylthymol blue complexometric procedure and phosphate by a modified phosphomolybdolate method (Dimension ${ }^{\circledR}$; Dade Behring, Eschborn, Germany).

The remainder of the blood sample was then separated into two aliquots of serum for analysis of $25(\mathrm{OH}) \mathrm{D}$ and $1,25(\mathrm{OH})_{2} \mathrm{D}$ and one aliquot of plasma for PTH assessment. Samples for PTH and $1,25(\mathrm{OH})_{2} \mathrm{D}$ were transported at $-20^{\circ} \mathrm{C}$, and $25(\mathrm{OH}) \mathrm{D}$ at $4^{\circ} \mathrm{C}$, as per laboratory guidelines.

$25(\mathrm{OH}) \mathrm{D}$ and PTH were analysed utilizing chemiluminescent immunoassay technology (Liaison ${ }^{\circledR} \quad 25-\mathrm{OH}$ Vitamin D Total Assay; Diasorin Inc., Saluggia (Vercelli), Italy). Sensitivity for $25(\mathrm{OH}) \mathrm{D}$ was $7 \mathrm{ng} / \mathrm{ml}$, below which levels were recorded as $<7 \mathrm{ng} / \mathrm{ml}$. The intra- and interassay CV was $7 \cdot 6-9 \cdot 4 \%$ and $9 \cdot 8-13 \cdot 4 \%$, respectively.

\section{Bone mineral density}

Dual-energy X-ray absorptiometry (DEXA; Osteocore III, Perols, France, version 5.22b) scanning was used to assess hip and spine bone mineral density (BMD) in thirty-nine of the screened sportsmen. The complete sample could not be assessed in the study period owing to accessibility issues to the DEXA machine, and athletes were imaged based on their availability during this period. Those athletes who completed DEXA scanning did not differ from the complete study group, other than having a significantly higher incidence of a family history of osteoporosis and fatigue fractures in elderly relatives. A certified technologist from the International Society of Clinical Densitometry performed all calibrations and measurements. The DEXA machine was calibrated each morning before the test. The CV for these records is $<1.01 \%$ in our laboratory. BMD was calculated in $\mathrm{g} / \mathrm{cm}^{2}$ for spine (L2-L4), hip-neck and hip-total. In addition, the clinical age-matched and gender-specific $Z$-score index was used to classify the BMD.

\section{Statistical analysis}

The relationships between the continuous variables were assessed by correlation and linear regression analysis. 
The relationships between the categorical variables were assessed by $\chi^{2}$ statistics. The relationship between a continuous and a categorical variable was assessed by one-way ANOVA. All continuous variables presented a normal distribution with a skewness index below 1 . Data are presented as mean and standard deviation. A $P$ value of $<0.05$ was considered statistically significant. Given the extremely low values of $25(\mathrm{OH}) \mathrm{D}$, results were divided into clinically relevant groups $(<10 \mathrm{ng} / \mathrm{ml}$, $10-<20 \mathrm{ng} / \mathrm{ml}, 20-<30 \mathrm{ng} / \mathrm{ml}$ ) for further evaluation.

\section{Results}

\section{Atblete characteristics}

As illustrated in Fig. 1, fifty-four (58\%) athletes had levels of $25(\mathrm{OH}) \mathrm{D}$ less than $10 \mathrm{ng} / \mathrm{ml}$ (mean age $20 \cdot 41$ (sD $7 \cdot 05)$ years, mean BMI $\left.22.59(\mathrm{sD} 3.58) \mathrm{kg} / \mathrm{m}^{2}\right)$, with a further thirty-one (33\%) having serum $25(\mathrm{OH}) \mathrm{D}$ less than $20 \mathrm{ng} / \mathrm{ml}$ (mean age 21.29 (sD 6.54) years, mean BMI $22 \cdot 13(\mathrm{SD} 4 \cdot 58) \mathrm{kg} / \mathrm{m}^{2}$ ). All remaining athletes had serum 25(OH)D less than $30 \mathrm{ng} / \mathrm{ml}$ (mean age 26.88 (sD 5.49) years, mean BMI $24.93(\mathrm{sD} 2 \cdot 41) \mathrm{kg} / \mathrm{m}^{2}$ ). No athlete

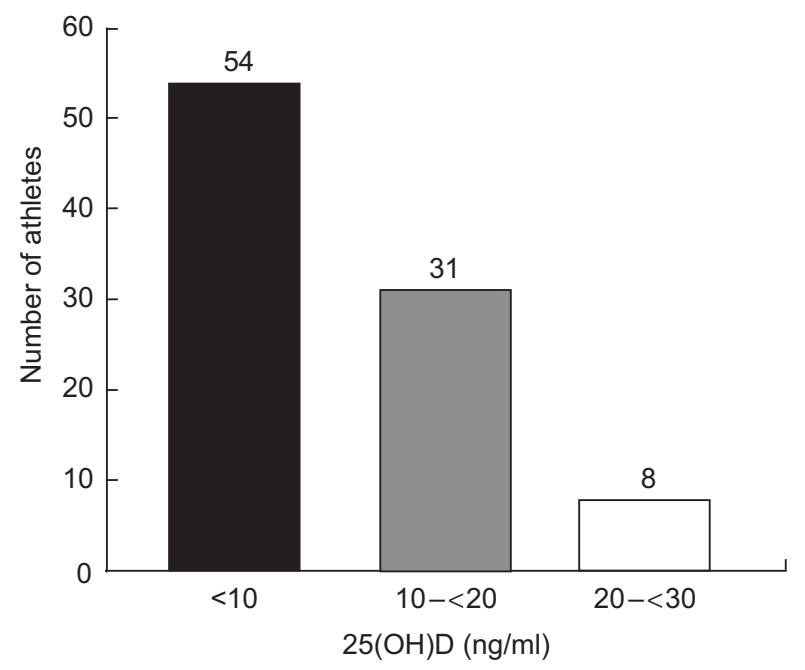

Fig. 1 Serum levels of 25-hydroxyvitamin D (25(OH)D) among ninety-three Middle Eastern male athletes presenting to hospital for an annual screening, Doha, Qatar, April-October 2008 described supplementing with oral vitamin D, although three athletes (3\%) used multivitamins which on investigation were found to contain vitamin $\mathrm{D}$, and thirty-two (34\%) utilized multivitamins for which the vitamin D content could not be confirmed. Eleven (12\%) athletes supplemented with Ca. Only six (7\%) athletes used sunscreen despite seventy-three (79\%) reportedly training outdoors $100 \%$ of the time. Despite most of the athletes reportedly completing all of their training outdoors, a third ( $n 31 ; 33 \%$ ) of athletes still described less than $30 \mathrm{~min}$ of daily sunlight exposure (total daily sunlight exposure: 30-60 $\mathrm{min}, \quad n 24$ (26\%); 60-120 min: $n 21$ (23\%); >120 min, $n 16(17 \%))$. The majority of athletes only exposed their hands and face, or less, to the sun on a regular basis (Table 1 ).

No athletes reported a history of stress fracture, but fourteen (15\%) athletes indicated a history of sixteen traumatic fractures including nine upper limb, five lower limb and one facial fracture. Seven (8\%) reported a family history of osteoporosis and fatigue fractures in elderly relatives. Fifty-one (55\%) athletes described a family history of diabetes, although the degree of relative and the type of diabetes are unclear. Skin colour was assessed as dark (21\%), olive (61\%) or fair (18\%), but was not formally assessed in four athletes (Table 2).

\section{Relationship between vitamin D status and otber parameters}

Our data showed that athletes with either deficiency (33\%) or severe deficiency $(58 \%)$ of $25(\mathrm{OH}) \mathrm{D}$ were significantly younger than the group with higher $25(\mathrm{OH}) \mathrm{D}$ concentrations $\left(F_{2,90}=3.2, P<0 \cdot 05\right.$; Fig. 2$)$. However, there were no significant differences in BMI between the three groups $\left(F_{2,88}=1 \cdot 5\right.$, NS; Fig. 2$)$, nor were there any significant differences in the variables estimated by the questionnaire between the groups with different 25(OH)D status: typical skin exposure $\left(\chi^{2}=0 \cdot 43\right.$, NS; Table 1$)$, skin colour $\left(\chi^{2}=3 \cdot 40\right.$, NS; Table 2$)$, sunlight exposure $\left(\chi^{2}=3 \cdot 77\right.$, NS). Furthermore, 25(OH)D status did not affect the Ca levels in the sample of athletes $\left(F_{2,90}=1 \cdot 1\right.$, NS; Fig. 2) but athletes with severe $25(\mathrm{OH}) \mathrm{D}$ deficiency displayed significantly higher PTH levels than the other groups $\left(F_{2,89}=6 \cdot 0, P<0 \cdot 05\right.$; Fig. 2$)$. There was

Table 1 Serum levels of 25-hydroxyvitamin D $(25(\mathrm{OH}) \mathrm{D})$ as a function of reported skin exposure to sunlight among ninety-three Middle Eastern male athletes presenting to hospital for an annual screening, Doha, Qatar, April-October 2008

\begin{tabular}{|c|c|c|c|c|c|c|c|c|}
\hline \multirow[b]{3}{*}{$25(\mathrm{OH}) \mathrm{D}(\mathrm{ng} / \mathrm{ml})$} & \multicolumn{6}{|c|}{ Typical skin exposure } & & \\
\hline & \multicolumn{2}{|c|}{ No skin } & \multicolumn{2}{|c|}{ Hands and face } & \multicolumn{2}{|c|}{ More than hands and face } & \multicolumn{2}{|c|}{ Total } \\
\hline & $n$ & $\%$ & $n$ & $\%$ & $n$ & $\%$ & $n$ & $\%$ \\
\hline$<10$ & 3 & 60 & 26 & 55 & 25 & 63 & 54 & $58 \cdot 7$ \\
\hline $10-<20$ & 2 & 40 & 16 & 34 & 12 & 30 & 30 & $32 \cdot 6$ \\
\hline $20-<30$ & 0 & 0 & 5 & 11 & 3 & 7 & 8 & 8.7 \\
\hline Total & 5 & 100 & 47 & 100 & 40 & 100 & 92 & 100 \\
\hline
\end{tabular}

Serum 25(OH)D was not dependent on the reported skin exposure $\left(\chi^{2}=0.43, \mathrm{NS}\right)$. 
no effect of the level of 25(OH)D deficiency on BMD (all $F_{2,36}<2 \cdot 1$, NS). The above results were unchanged when age was considered as a covariate. Our results suggested a prevalence of low BMD, with only sixteen of thirty-nine athletes (41\%) presenting with $Z$-scores higher than -1 and twenty-three of thirty-nine (59\%) having at least one $Z$-score below -1 .

\section{Discussion}

The major finding of the present study is that young, active Middle Eastern males have an extremely high

Table 2 Serum levels of 25-hydroxyvitamin D (25(OH)D) as a function of skin colour among ninety-three Middle Eastern male athletes presenting to hospital for an annual screening, Doha, Qatar, April-October 2008

\begin{tabular}{|c|c|c|c|c|c|c|c|c|}
\hline \multirow[b]{3}{*}{$25(\mathrm{OH}) \mathrm{D}(\mathrm{ng} / \mathrm{ml})$} & \multicolumn{6}{|c|}{ Skin colour } & & \\
\hline & \multicolumn{2}{|c|}{ Dark } & \multicolumn{2}{|c|}{ Olive } & \multicolumn{2}{|c|}{ Fair } & \multicolumn{2}{|c|}{ Total } \\
\hline & $n$ & $\%$ & $n$ & $\%$ & $n$ & $\%$ & $n$ & $\%$ \\
\hline$<10$ & 13 & 68 & 33 & 61 & 6 & 38 & 52 & $58 \cdot 4$ \\
\hline $10-<20$ & 6 & 32 & 16 & 30 & 7 & 44 & 29 & $32 \cdot 6$ \\
\hline $20-<30$ & 0 & 0 & 5 & 9 & 3 & 19 & 8 & $9 \cdot 0$ \\
\hline Total & 19 & 100 & 54 & 100 & 16 & 100 & 89 & 100 \\
\hline
\end{tabular}

Serum 25(OH)D was not dependent on the reported skin colour $\left(\chi^{2}=3 \cdot 40\right.$, NS).
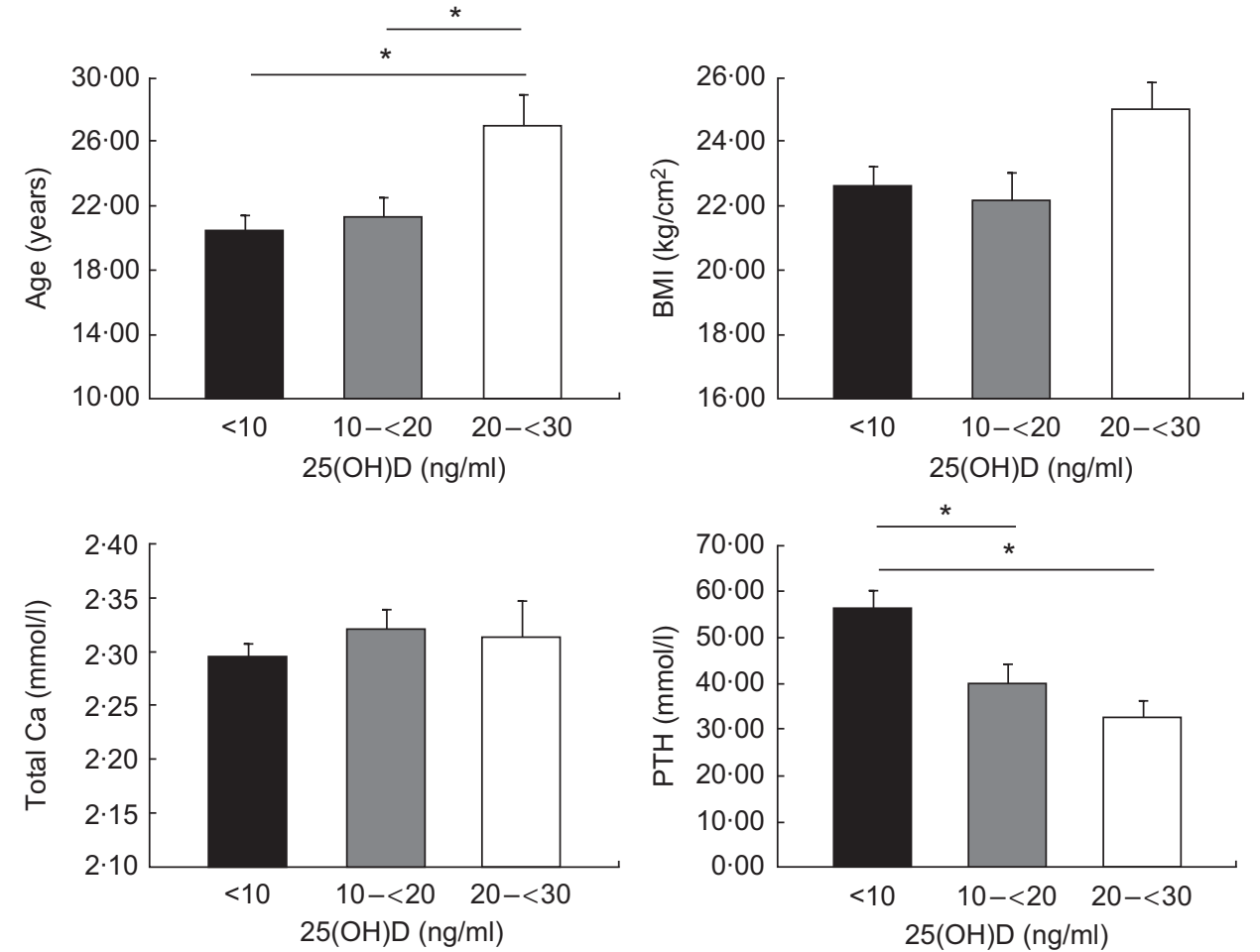

Fig. 2 Relationship between serum levels of 25-hydroxyvitamin $\mathrm{D}(25(\mathrm{OH}) \mathrm{D})$ and mean age, BMI, total Ca and parathyroid hormone (PTH) among ninety-three Middle Eastern male athletes presenting to hospital for an annual screening, Doha, Qatar, April-October 2008. Values are means with standard deviations represented by vertical bars. Mean values were significantly different between groups: ${ }^{\star} P<0.05$ prevalence of $25(\mathrm{OH}) \mathrm{D}$ deficiency. All of our sample of athletes had suboptimal 25(OH)D concentration, with $58 \%$ having severe vitamin D deficiency and a further $32 \%$ being deficient. The levels of deficiency observed are as high as or higher than those previously described in non-athletic groups of Middle Eastern men and women $^{(15,24,26,36)}$.

$1,25(\mathrm{OH}) 2 \mathrm{D}$ is an essential component of $\mathrm{Ca}$ and $\mathrm{P}$ metabolism, with low levels resulting in impaired $\mathrm{Ca}$ absorption, elevation of PTH and osteopenia ${ }^{(37,38)}$. Of note, in the present study we observed an inverse relationship between 25(OH)D concentration and PTH, but no relation with total $\mathrm{Ca}$ or BMD. While in many cases the exact mechanisms are yet to be elucidated, $25(\mathrm{OH}) \mathrm{D}$ is also recognized as being associated with chronic health conditions including diabetes and bowel cancer ${ }^{(5)}$. It is interesting to note that these conditions are among the most pressing issues facing the health-care system in Qatar ${ }^{(39)}$. While 25(OH)D deficiency has been well described in Middle Eastern women ${ }^{(22-24)}$, and increasingly is recognized as a worldwide phenomenon, there is a paucity of literature regarding the $25(\mathrm{OH}) \mathrm{D}$ status of Middle Eastern men ${ }^{(15,25)}$. The present study confirms that Middle Eastern men are also vulnerable to $25(\mathrm{OH}) \mathrm{D}$ deficiency.

Numerous factors including absolute sunlight exposure, insufficient dietary vitamin $\mathrm{D}$, malabsorption of dietary vitamin D, UV light insulation due to atmospheric 
dust particles, altered vitamin D metabolism and the use of concealing clothing have all been postulated as factors involved in the prevalence of vitamin D deficiency in the Middle East ${ }^{(26,40)}$. We found no relationship between $25(\mathrm{OH}) \mathrm{D}$ concentration in men and training either in or out of doors, use of sunscreen, sunlight exposure or skin coverage. While the wearing of concealing clothing has been associated with vitamin D deficiency in Middle Eastern women ${ }^{(23,24)}$, our data show no such relationship between sunlight/skin exposure and 25(OH)D concentration. This lack of association has been noted previously in both Middle Eastern and northern hemisphere countries $^{(15,18)}$. Even in adolescents with high levels of unprotected sunlight exposure, 25(OH)D concentrations have been found to be low ${ }^{(14)}$. In our sample, the majority exposed only limited amounts of skin (Table 1) and a third of the athletes described less than $30 \mathrm{~min}$ of daily sunlight exposure. While not formally assessed, it is our observation that as a result of heat and other social factors, most outdoor training is in fact performed after sunset, suggesting that actual effective UVB exposure may be low. Furthermore, we observed a non-significant trend for darker skin to be associated with a lower concentration of $25(\mathrm{OH}) \mathrm{D}$. This reflects the photo-protective effect of skin pigmentation ${ }^{(41,42)}$, and further supports the speculation that effective UVB exposure is the principal cause of the $25(\mathrm{OH}) \mathrm{D}$ deficiency in this cohort. Lack of a range of normal $25(\mathrm{OH}) \mathrm{D}$ levels may have contributed to this lack of association and hence the actual impact of exposure to sunlight on $25(\mathrm{OH}) \mathrm{D}$ concentration in this cohort requires further evaluation.

Of note, athletes with low $25(\mathrm{OH}) \mathrm{D}$ were significantly younger than those with higher levels. This finding is consistent with some authors ${ }^{(15)}$ but not others ${ }^{(36)}$, and may reflect increased sunlight exposure with increasing age or altered vitamin D metabolism with increasing age. BMI and smoking have previously been shown to have a negative association with $25(\mathrm{OH}) \mathrm{D}$ concentration, but this was not illustrated in the current group of athletes ${ }^{(18)}$. However, these trends need to be considered against the uniformly deficient $25(\mathrm{OH}) \mathrm{D}$ concentration in this cohort, restricting the likelihood of finding an association.

Given the reported relationship between 25(OH)D, BMD and bone stress injuries ${ }^{(17,35)}$, it is not surprising that $59 \%$ of our sample was found to have low BMD (at least one $Z$-score below -1 ). Hannan et al. ${ }^{(17)}$ reported significant ethnic differences on the impact of $25(\mathrm{OH}) \mathrm{D}$ concentration and BMD, with white men having a strong correlation between 25(OH)D concentration and BMD but no such relationship being present in black or Hispanic men. Our data showed that BMD and 25(OH)D were not statistically linked in a sample of Middle Eastern male athletes. It is possible that genetic polymorphism in the $25(\mathrm{OH}) \mathrm{D} / 1,25(\mathrm{OH})_{2} \mathrm{D}$ pathway may potentially account for some of these differences, and this warrants further investigation ${ }^{(43)}$. However, it is interesting that in this cohort of athletes with low levels of $25(\mathrm{OH}) \mathrm{D}$, inversely elevated PTH and low BMD, there were no reported stress fractures. This may be a result of a number of factors including the training intensity, age of subjects or other protective mechanisms within the cohort.

In the mid-20th century athletes were supposedly using UV light as a performance aid, although scientific evidence to support its use was limited ${ }^{(29-31)}$. Severe $25(\mathrm{OH}) \mathrm{D}$ deficiency is known to be associated with reduced type II muscle fibre composition ${ }^{(44-47)}$ and the sarcopenia associated with ageing is thought to be affected by $25(\mathrm{OH}) \mathrm{D}$ concentrations ${ }^{(48-50)}$. Recently, $25(\mathrm{OH}) \mathrm{D}$ deficiency was shown to be associated with reduced physical performance both in young and aged populations ${ }^{(32,44)}$. Given the accumulating evidence from numerous sources implicating $1,25(\mathrm{OH})_{2} \mathrm{D}$ and its metabolic pathways in the optimal functioning of skeletal muscle, it is important that young athletes have appropriate $25(\mathrm{OH}) \mathrm{D}$ concentrations. This is not currently being achieved in this cohort. Safe and appropriate levels of sunlight exposure should be sufficient to provide adequate $25(\mathrm{OH}) \mathrm{D}$ concentrations in this cohort. However, the cultural practice of wearing concealing clothing, combined with intense heat that is not conducive to spending time in the sun, makes this difficult to achieve. Furthermore, as food is not currently fortified with dietary vitamin D in Qatar, the routine supplementation of athletes in the Middle East may be required. Given that the treatment of $25(\mathrm{OH}) \mathrm{D}$ deficiency has been shown to be both safe and efficacious, the inclusion of $25(\mathrm{OH}) \mathrm{D}$ assessments in athlete screening is warranted. Management of $25(\mathrm{OH}) \mathrm{D}$ deficiency should include education regarding appropriate sunlight exposure and either oral or intramuscular correction of deficiencies ${ }^{(1)}$. In those athletes not screened for 25(OH)D deficiency, routine advice on appropriate sunlight exposure should be provided. However, the merits of routine supplementation in this cohort without 25(OH)D assessment are unclear. Unfortunately, in many regions $25(\mathrm{OH}) \mathrm{D}$ continues to be an expensive assessment and there continues to be concern about inter-laboratory variability, and as a result it is often not part of a routine assessment ${ }^{(51)}$.

\section{Conclusions}

The current trial suggests that $25(\mathrm{OH}) \mathrm{D}$ deficiency is endemic in Middle Eastern sportsmen. With such high rates of $25(\mathrm{OH}) \mathrm{D}$ deficiency in a young active population (91\%), longitudinal trials should be performed to assess the impact of this deficiency early in life on long-term health outcomes in an otherwise healthy and active cohort. Given the potential for both significant short- and long-term consequences of $25(\mathrm{OH}) \mathrm{D}$ deficiency, evaluation and management of $25(\mathrm{OH}) \mathrm{D}$ deficiency should be included as part of the routine assessment of athletes in 
this region of the world. Furthermore, treatment of this deficiency would appear critical if this group is not to be at elevated risk of chronic health issues in the future.

\section{Acknowledgements}

Sources of funding: Funding for this project was internal, with no external grants received. Conflict of interest declaration: The authors have no known conflict of interest. Author contributions: B.H. contributed to the concept, study design and development, results collation and evaluation, and manuscript preparation. J.G. contributed to the study design and implementation, data analysis, and manuscript preparation and review. S.R. contributed to the study design, data collation and statistical analysis, and manuscript review. H.C. had overall project responsibility, contributed to the study concept and preparation, data review and manuscript review, and made the decision regarding submission. Acknowledgements: The authors would like to acknowledge the work of Dr Cristiano Eirale, Dr Claude Tremblay, Dr Massimilliano Sala, Dr Jean-Claude Chatard and Dr Justin Paoloni in the collection of data, and the support of Nellie Khalil, Sirine Boukarroum and Paschal Tahtouh in data collection and collation.

\section{References}

1. Holick M (2007) Vitamin D deficiency. $N$ Engl J Med 357, 266-281.

2. Holick M (2006) High prevalence of vitamin D inadequacy and implications for health. Mayo Clin Proc 81, 353-373.

3. Malloy P, Pike J \& Feldman D (1999) The vitamin D receptor and the syndrome of hereditary 1,25-dihydroxyvitamin D-resistant rickets. Endocr Rev 20, 156-188.

4. Lappe J, Travers-Gastafson D, Davies K et al. (2007) Vitamin D and calcium supplementation reduces cancer risk: results of a randomized trial. Am J Clin Nutr 85, 1586-1591.

5. Holick M (2004) Vitamin D: importance in the prevention of cancers, type 1 diabetes, heart disease, and osteoporosis. Am J Clin Nutr 79, 362-371.

6. Pittas A, Lau J, Hu F et al. (2007) The role of vitamin D and calcium in type 2 diabetes. A systematic review and metaanalysis. J Clin Endocrinol Metab 92, 2017-2029.

7. Hypponen E, Laara E, Reunanen A et al. (2001) Intake of vitamin $\mathrm{D}$ and risk of type 1 diabetes: a birth-cohort study. Lancet 358, 1500-1503.

8. Dietrich T, Joshipura K, Dawson-Hughes B et al. (2004) Association between serum concentrations of 25-hydroxyvitamin $\mathrm{D}_{3}$ and periodontal disease in the US population. Am J Clin Nutr 80, 108-113.

9. Giovannucci E, Liu Y, Rimm E et al. (2006) Prospective study of predictors of vitamin D status and cancer incidence and mortality in men. J Natl Cancer Inst 98, 451-459.

10. Hypponen E, Boucher B, Berry D et al. (2008) 25Hydroxyvitamin D, IGF-1, and metabolic syndrome at 45 years of age. Diabetes 57, 298-305.

11. Pani M, Knapp M, Donner H et al. (2000) Vitamin D receptor allele combinations influence genetic susceptibility to type 1 diabetes in Germans. Diabetes 49 , 504-507.
12. Garland C, Garland F, Gorham E et al. (2006) The role of vitamin D in cancer prevention. Am J Public Health 96, 252-261.

13. Malabanan A, Veronikis I \& Holick M (1998) Redefining vitamin D insufficiency. Lancet 351, 805-806.

14. Binkley N, Novotny R, Krueger D et al. (2007) Low vitamin D status despite abundant sun exposure. J Clin Endocrinol Metab 92, 2130-2135.

15. Hashemipour S, Larijani B, Adibi H et al. (2004) Vitamin D deficiency and causative factors in the population of Tehran. BMC Public Health 4, 38.

16. Gordon C, DePeter K, Feldman H et al. (2004) Prevalence of vitamin D deficiency among healthy adolescents. Arch Pediatr Adolesc Med 158, 531-537.

17. Hannan MT, Litman HJ, Araujo AB et al. (2008) Serum 25hydroxyvitamin $\mathrm{D}$ and bone mineral density in a racially and ethnically diverse group of men. J Clin Endocrinol Metab 93, 40-46.

18. Andersen R, Molgaard C, Skovgaard L et al. (2005) Teenage girls and elderly women living in northern Europe have low winter vitamin D status. Eur J Clin Nutr 59, 533-541.

19. Nowson CA \& Margerison C (2002) Vitamin D intake and vitamin D status of Australians. Med J Aust 177, 149-152.

20. Rockell J, Green T, Skeaff C et al. (2005) Season and ethnicity are determinants of serum 25-hydroxyvitamin D concentrations in New Zealand children aged 5-15 y. J Nutr 135, 2602-2608.

21. Lovell G (2008) Vitamin D status of females in an elite gymnastics program. Clin J Sport Med 18, 159-161.

22. Allali F, El Aichaoui S, Saoud B et al. (2006) The impact of clothing style on bone mineral density among post menopausal women in Morocco: a case-control study. BMC Public Health 6, 135.

23. Fonseca V, Tongia R, El-Hazmi M et al. (1984) Exposure to sunlight and vitamin D deficiency in Saudi Arabian women. Postgrad Med J 60, 589-591.

24. Hatun S, Islam O, Cizmecioglu F et al. (2005) Subclinical vitamin $\mathrm{D}$ deficiency is increased in adolescent girls who wear concealing clothing. J Nutr 135, 218-222.

25. Siam A, Hammoudeh M, Bener I et al. (2006) Vitamin-D deficiency in Qatar. APLAR J Rheumatol 9, Suppl. 1, A32-A33.

26. Sedrani S, Wahab A, Elidrissy T et al. (1983) Sunlight and vitamin D status in normal Saudi subjects. Am J Clin Nutr 38, 129-132.

27. Willis K, Peterson N \& Larson-Meyer D (2008) Should we be concerned about the vitamin D status of athletes? Int $J$ Sport Nutr Exerc Metab 18, 204-224.

28. Lehtonen-Veromaa M, Mottonen T, Irjala K et al. (1999) Vitamin D intake is low and hypovitaminosis D common in healthy 9- to 15-year-old Finnish girls. Eur J Clin Nutr 53, 746-751.

29. Cannell J, Hollis B, Sorenson M et al. (2009) Athletic performance and vitamin D. Med Sci Sports Exerc 41, 1102-1110.

30. Allen R \& Cureton T (1945) Effects of ultraviolet radiation on physical fitness. Arch Phys Med 26, 641-644.

31. Hoberman J (1992) Faster, higher, stronger. A history of doping in sport. In Mortal Engines: The Science of Performance and the Dehumanization of Sport, pp. 100-153. New York: The Free Press.

32. Ward K, Das G, Berry J et al. (2009) Vitamin D status and muscle function in post-menarchal adolescent girls. J Clin Endocrinol Metab 94, 559-563.

33. El-Hajj G, Nabulsi M, Tamim H et al. (2006) Effect of vitamin D replacement on musculoskeletal parameters in school children: a randomized controlled trial. J Clin Endocrinol Metab 91, 405-412.

34. Ruohola J, Laaksi I, Ylikomi T et al. (2006) Association between serum $25(\mathrm{OH}) \mathrm{D}$ concentrations and bone stress 
fractures in Finnish young men. J Bone Miner Res 21, 1483-1488.

35. Lappe J, Cullen D, Haynatzki G et al. (2008) Calcium and vitamin D supplementation decreases incidence of stress fractures in female navy recruits. J Bone Miner Res 23, 741-749.

36. Sedrani S (1984) Vitamin D status of Saudi men. Trop Geogr Med 36, 181-187.

37. Tang B, Eslick G, Nowson CA et al. (2007) Use of calcium or calcium in combination with vitamin D supplementation to prevent fractures and bone loss in people aged 50 years and older; a meta-analysis. Lancet 370, 657-666.

38. Abrams S, Grifin I, Hawthorne K et al. (2005) Relationships among vitamin D levels, PTH, and calcium absorption in young adolescents. J Clin Endocrinol Metab 90, 5576-5581.

39. Chanpong G (2008) Qatar 2006 World Health Survey: Overview. Presentation. Doha: National Health Authority.

40. Awumey E, Mitra D, Hollis B et al. (1998) Vitamin D metabolism is altered in Asian Indians in the southern United States: a clinical research center study. J Clin Endocrinol Metab 83, 169-173.

41. Matsuoka L, Wortsman J, Haddad JG et al. (1991) Racial pigmentation and the cutaneous synthesis of vitamin D. Arch Dermatol 127, 536-538.

42. Clemens T, Adams J, Henderson S et al. (1982) Increased skin pigment reduces the capacity of skin to synthesise vitamin D3. Lancet 1, 74-76.

43. Rabon-Stith K, Hagberg J, Phares D et al. (2005) Vitamin D receptor FokI genotype influences bone mineral density response to strength training, but not aerobic training. Exp Physiol 90, 653-661.

44. Glerup H, Mikkelsen K, Poulsen L et al. (2000) Hypovitaminosis D myopathy without biochemical signs of osteomalacic bone involvement. Calcif Tissue Int 66, 419-424.

45. Irani P (1976) Electromyography in nutritional osteomalacic myopathy. J Neurol Neurosurg Psychiatry 39, 686-693.

46. Sato Y, Iwamoto J, Kanoko R et al. (2005) Low-dose vitamin D prevents muscular atrophy and reduces falls and hip fractures in women after stroke: a randomized controlled trial. Cerebrovasc Dis 20, 187-192.

47. Russell J (1994) Osteomalacic myopathy. Muscle Nerve 17, 578-580.

48. Gerdhem P, Ringsberg K, Obrant K et al. (2005) Association between 25-hydroxy vitamin $\mathrm{D}$ levels, physical activity, muscle strength and fractures in the prospective population-based OPRA Study of Elderly Women. Osteoporos Int 16, 1425-1431.

49. Bischoff H, Stahelin H, Urscheler N et al. (1999) Muscle strength in the elderly: its relation to vitamin D metabolites. Arch Phys Med Rehabil 80, 54-58.

50. Visser M, Deeg D \& Lips P (2003) Low vitamin D and high parathyroid hormone levels as determinants of loss of muscle strength and muscle mass (sarcopenia): the Longitudinal Aging Study Amsterdam. J Clin Endocrinol Metab 88, 5766-5772.

51. Binkley N, Kreuger K, Cowgill C et al. (2004) Assay variation confounds the diagnosis of hypovitaminosis D: a call for standardization. J Clin Endocrinol Metab 89, 3152-3157. 